\title{
Study of the pre-schoolers uniforms of Chandigarh schools
}

\author{
LALITA RANI AND JETINDER SOHI
}

Received: 07.07.2017; Revised: 01.11.2017; Accepted: 15.11.2017

See end of the paper for authors' affiliations
ABSTRACT : School uniforms are the distinctive design clothing worn by the students of schools and are purposely designed for undifferentiated identification. The study aims to find out the suitability of the uniforms to the pre-school children and to find out the features required in the uniforms of the pre-school children. The study dealt with the uniforms of pre-school children which required meeting with teachers and mothers, and observing the uniforms of children. Therefore, survey method was used that included interview and observation. The major findings shows that regarding various features that should be there in the uniforms, the mothers preferred comfort followed by smartness and appeal of the uniform and good colour combination. Ease to care and self-help were at fourth and fifth place. A good style and its suitability of style to season were the next preferred factors. Other factors in their order of preference were durability and serviceability, economy, room for growth and colourfastness was the last rank given by the mothers of the preschooler's uniform. Mothers found that uniforms were colourfast and were economical too.

KEY WORDS: School uniforms, Suitability, Durability, Colourfastness, Pre-school children

- HOW TO CITE THIS PAPER : Rani, Lalita and Sohi, Jetinder (2017). Study of the pre-schoolers uniforms of Chandigarh schools. Asian J. Home Sci., 12 (2) : 574-578, DOI: 10.15740/HAS/AJHS/12.2/ 574-578. 